ISSN: 0514-7336

DOI: http://dx.doi.org/10.14201/zephyrus201882167185

\title{
EL PÓRTICO DEL RECINTO DE CULTO A DIVUS AUGUSTUS EN LA ACRÓPOLIS DE TARRACO: LA DECORACIÓN DEL ÁTICO Y SU REFLEJO EN LAS CIUDADES ROMANAS DE LA GALIA
}

\section{The portico of the cult precinct to Divus Augustus on the acropolis at Tarraco: the decoration of the attic and its reflection in the Roman cities of the Galia}

\author{
Antonio Peña Jurado \\ Dpto. de Arte y Musicología. Facultad de Filosofía y Letras-UAB. Campus de Bellaterra, Edificio B. 08193 Cerdanyola \\ del Vallès (Barcelona). Correo-e: antonio.pena@uab.cat. ORCID ID: 0000-0002-1763-4355
}

Recepción: 5/02/2018; Revisión: 22/06/2018; Aceptación: 2/09/2018

\begin{abstract}
Resumen: Presentamos en este artículo una nueva propuesta de reconstrucción del ático del pórtico que en época flavia rodeaba el recinto de culto dedicado a Divus Augustus, situado en la acrópolis de Tarragona. La hipótesis se sustenta en dos argumentos: por una parte, la evidencia proporcionada por el muro de cierre del pórtico y la medición precisa de los elementos arquitectónicos correspondientes a la columnata y al ático; y, por otra, la existencia de paralelos en algunas ciudades de la Galia, caso de Arlés, Nyon y Avenches. Aunque tradicionalmente se ha propuesto que el origen de los motivos que decoraban el ático radica en el ático del pórtico del Foro de Augusto, las divergencias entre uno y otro sugieren pensar en otro prototipo. En este sentido, cabe plantear dos opciones: la primera, que el modelo se encuentre en Roma. En ese caso, en virtud de la datación flavia de los elementos arquitectónicos, podría pensarse en el pórtico del Templum Pacis, también dotado de un ático, si bien hasta la fecha no se conocen elementos arquitectónicos similares que puedan atribuírsele; o, la segunda, que el pórtico de Tarragona fuera un prototipo en sí mismo, de manera que los recintos de la Galia con iconografía y datación similar derivarían directamente de él.

Palabras clave: periodo flavio; arquitectura romana; Arlés; Nyon; Avenches; Templum Pacis.
\end{abstract}

AвSTRACT: We present in this paper a new reconstruction proposal for the attic of the portico that in the Flavian period surrounded the cult precinct dedicated to Divus Augustus, located on the acropolis at Tarragona. This hypothesis is based on two arguments: on the one hand, the evidence provided by the rear wall of the portico and the precise measuring of the architectural elements corresponding to the colonnade and the attic; and, on the other hand, the existence of parallels in some cities of the Galia, such as Arles, Nyon and Avenches. Although it has been traditionally proposed that the origin of the motifs decorating the attic was in the attic of the portico at the Forum of Augustus, divergences between one and the other suggest thinking about another prototype. In this sense, two options can be proposed: the first, that the model stands at Rome. In that case, by virtue of the Flavian dating of the architectural elements, the portico of the Templum Pacis also endowed with an attic could be considered, even if no similar architectural elements are known up to date that can be attributed 
to it; or, the second, that the portico at Tarragona was a prototype in itself, so that the Gallian precincts with similar iconography and dating would be directly derived from it.

Key words: Flavian period; Roman architecture; Arlés; Nyon; Avenches; Templum Pacis.

\section{Introducción ${ }^{1}$}

Como es bien conocido, sobre la acrópolis de Tarraco, capital de la provincia Hispania anterior (Fig. 1), a lo largo del s. I d. C. se construyó un conjunto de edificios estructurado en tres terrazas (Fig. 2): la superior, sede de un recinto de culto imperial; la central, donde se alzaba una imponente plaza; y la inferior, ocupada por un circo ${ }^{2}$. De todas estas construcciones, probablemente el mayor interés lo ha despertado el recinto de culto de la terraza superior, en cuyo interior se alza hoy la catedral medieval. Pionero en su estudio fue, sin duda, Hauschild (19721974, 1983, 1992 y 2009), quien durante las décadas de 1970 y 1980 llevó

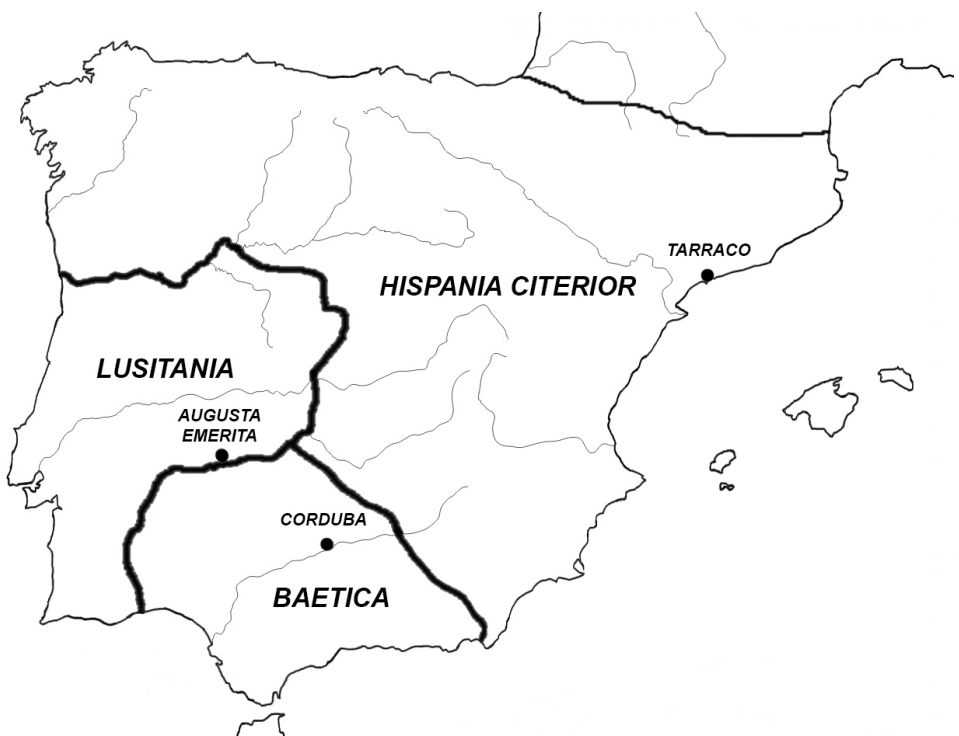

FIG. 1. Mapa de Hispania en época altoimperial con indicación de las provincias y situación de sus respectivas capitales. a cabo la documentación de los muros conservados, así como varias excavaciones en el entorno de la catedral. No menos importante fue la labor desarrollada en la década de 1980 por Dupré y por el Ted'A (1989: 151-167), sobre todo en lo que respecta al desarrollo de nuevas excavaciones en varios sectores del recinto. Desde principios de los años 90 el

1 Trabajo realizado en el marco del grupo de investigación ArPA (ICAC), financiado por la Generalitat de Catalunya.

2 La bibliografía sobre el tema es extensísima, de ahí que solo mencionemos los trabajos de mayor relevancia. En general sobre el conjunto: Ted'A, 1989 y Macias et al., 2007a: 40-46; cf. también Vinci, S.: El 'Foro Provincial' de Tarraco: documentación de análisis de técnicas y procesos de construcción. Tesis doctoral inédita defendida en 2014 en Tarragona. Sobre la plaza: Ted'A, 1989: 167-182; Dupré y Carreté, 1993; Güell et al., 1993; Pociña y Remolà, 2000; Mar et al., 2015: 131-169. Sobre el circo: Dupré et al., 1988; Ruiz de Arbulo y Mar, 2001; Mar et al., 2015: 171-211; Miró, 2017; cf. también Piñol, L.: El circ romà de Tarragona: noves interpretacions arqueològiques. Estudi històric-arquitectònic de l'edifici. Memoria de Licenciatura inédita presentada en 1995 en Tarragona. testigo ha sido recogido por el equipo comandado por Mar y Ruiz de Arbulo que, partiendo de la revisión de las excavaciones previas, las estructuras y los elementos arquitectónicos conservados, han publicado numerosos estudios (Mar, 1993; Pensabene y Mar, 2004; Mar y Pensabene, 2009 y 2010; Pensabene y Mar, 2010: 243-277), cuyos principales resultados han sido reunidos en dos monografías de muy reciente aparición (Mar et al., 2012: 348374; 2015: 83-129). Junto a ello, desde comienzos del s. XXI, otro equipo integrado por Macias, Menchón, Muñoz y Teixell ha reactivado el estado de la cuestión al presentar nuevos datos producto de las diferentes actividades arqueológicas que han tenido ocasión de realizar tanto en el interior de la catedral como en su entorno inmediato. Esa labor se ha plasmado igualmente en numerosas publicaciones (Macias et al., 2007b: 160-188; 2007c; 2010a y b; 2010-2011; 2011; 2012 y 2014)3. En los últimos

3 Para un comentario más detallado sobre la historiografía y la historia de la investigación del recinto: Hauschild, 


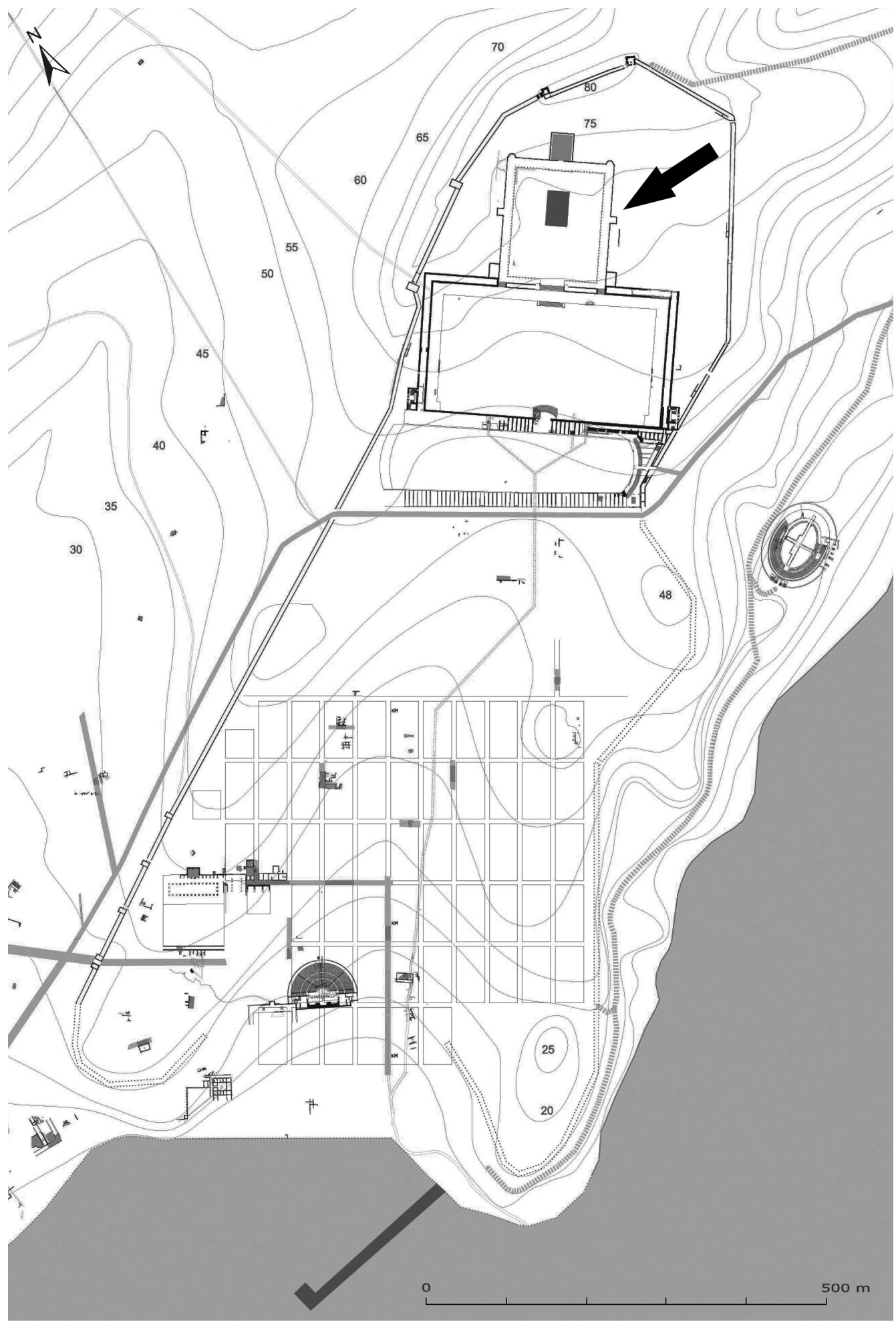

Fig. 2. Planta de Tarraco en el s. II d. C.; en la parte superior se encuentran los edificios de la acrópolis. La flecha indica la ubicación del recinto de culto a Divus Augustus (Macias et al., 2007a: plano IV). 
años, también nosotros hemos prestado atención al recinto, especialmente en lo que respecta a sus elementos arquitectónicos. Fruto de la revisión de los materiales atribuibles a este espacio, ya publicados por Gimeno (1991) y Pensabene (1993), y de las estructuras documentadas por Hauschild es la propuesta que presentamos a continuación sobre el pórtico del recinto en época flavia, más concretamente sobre el aspecto que debió tener su ático.

\section{El recinto de culto a Divus Augustus}

Tal y como lo conocemos hoy en día, el recinto de culto era un espacio de unos $133 \mathrm{~m}$ de anchura y 156 m de longitud delimitado por un tripórtico en forma de $\Pi$ provisto de exedras cuadradas y semicirculares en los brazos laterales y una gran sala de unos $29 \mathrm{~m}$ de anchura dispuesta en el eje del brazo septentrional. Al s, una gran escalinata axial de casi $30 \mathrm{~m}$ de anchura y posiblemente dos más pequeñas situadas en el extremo de los pórticos laterales ponían en conexión el recinto con la plaza de la terraza intermedia (Macias et al., 2007a: 32, fig. 22) (Fig. 3). Si bien en un principio se pensó que el complejo era una obra ex novo de época flavia (Ted'A, 1989: 158-160; Mar, 1993: 111-113), en 2004 Mar propuso que en realidad constituía una ampliación de época flavia de un recinto preexistente, fechado en época tiberiana, presidido por el afamado templo dedicado a Divus Augustus, situado en el emplazamiento de la catedral (Pensabene y Mar, 2004: 83-86) ${ }^{4}$. La confirmación de

1983: 89-94; Ted'A, 1989: 142-149; Mar, 1993: 107-111; Macias et al., 2007b: 157-160; Macias et al., 2010a: 425430; Vinci, op. cit. n. 2: 45-54.

4 Hasta entonces, el edificio solo era conocido por las fuentes literarias y numismáticas. En efecto, según constata Tácito (Ann. I, 78), en el año 15 d. C. una embajada de ciudadanos de la Hispania Citerior marchó a Roma para solicitar permiso al emperador Tiberio para la construcción del templo en Tarragona, permiso que fue concedido. Las monedas acunadas en la ciudad en época tiberiana transmiten la imagen del edificio, representado como un templo octástilo situado sobre un estilóbato o sobre un podio (Burnett et al., 1992: 104-105, n. ${ }^{\text {ss } 219, ~ 222, ~} 224$ y 226, lám. 16). esta hipótesis se produjo unos años después gracias a diferentes actividades arqueológicas: primeramente, en 2007 el equipo formado por Macias, Menchón, Muñoz y Teixell llevó a cabo prospecciones geofísicas en el interior de la catedral que demostraron la existencia bajo su nave central de una estructura de unos $27 \mathrm{~m}$ de anchura que aparentemente cabía poner en relación con el citado templo (Casas et al., 2009: 281, fig. 8; Macias et al., 2010a: 435, n. 9, 436; Macias et al., 2010b: 55); unos ańos después, en 2010 y 2011 las excavaciones realizadas por Macias, Muñoz y Teixell bajo la nave central de la catedral documentaron una plataforma de opus caementicium de 2,30 m de grosor, interpretable como la plataforma sobre la que apoyaba la cimentación de sillares del podio (Macias et al., 2012: 154, n. 7). A favor de la identificación de esta estructura con el templo de Divus Augustus podría manifestarse también una inscripción fragmentaria encontrada en las excavaciones realizadas en 2000 por Menchón, Muñoz y Teixell junto a la capilla de San Salvador, al o del claustro de la catedral. Según la reciente propuesta de Gorostidi, Macias, Muñoz, Rodà, Teixell y nosotros mismos (Peña et al., 2015), muy probablemente en ella estaría mencionado el templo. En virtud de la evidencia arqueológica y de los fragmentos marmóreos de fuste de grandes dimensiones procedentes del entorno cercano, cabe reconstruir un templo de 30 x $53 \mathrm{~m}$, octástilo y quizá períptero sine postico, según su posible modelo, el templo de Mars Ultor (Macias et al., 2014: 1542) 5 . A excepción de algunos otros elementos arquitectónicos atribuibles a su alzado (Pensabene y Mar, 2010: 258-262, 266, n. 64), no se ha conservado resto alguno del mismo.

Como hemos señalado antes, según la propuesta de Mar el edificio surgía en el interior de un recinto porticado, también construido en época tiberiana. Sin embargo, de este pórtico no queda resto alguno pues fue desmantelado en época flavia para ampliar el

5 Pensabene y Mar (2010: 251, fig. 6) son de otra opinión, pues restituyen un edificio octástilo períptero de unos 31 x $64 \mathrm{~m}$. En general sobre el templo: Pensabene y Mar, 2010: 243-277; Mar et al., 2012: 348-374. 


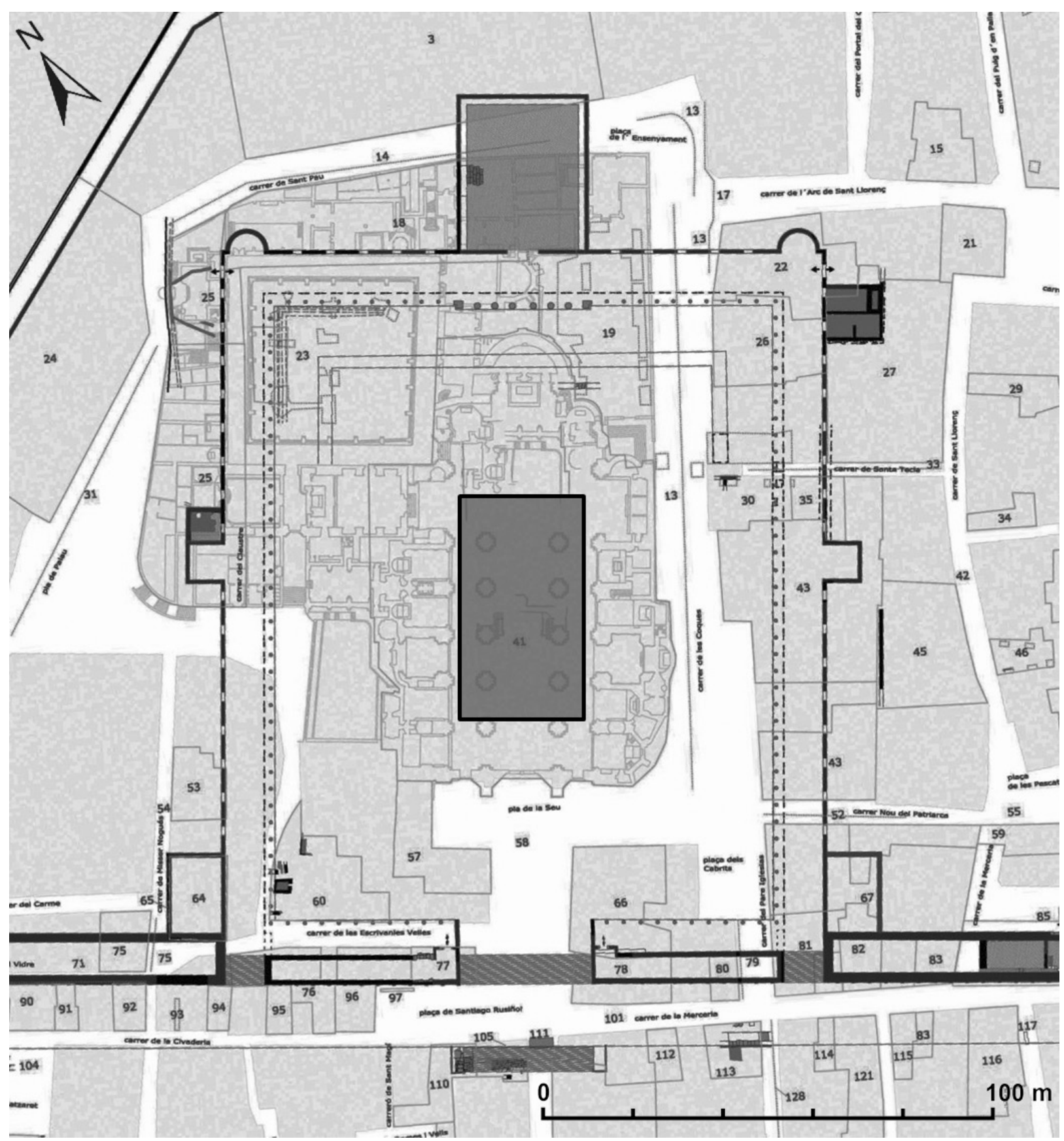

Fig. 3. Planta del recinto de culto en época flavia con situación del templo de Divus Augustus (Macias et al., 2007a: plano A). Tamaño y posición del templo modificados por el autor.

recinto y construir uno nuevo. En su opinión, testimonio de este primer pórtico sería la zanja documentada por Sánchez Real (1969: 279-280 y 278, fig. 2) en sus excavaciones en el claustro de la catedral, producto del desmonte de la cimentación de sillares del muro de cierre de dicha construcción (Pensabene y Mar, 2004: 83)6. La datación flavia del segundo

6 Mar hace coincidir el límite septentrional del recinto con el muro N del claustro (Pensabene y Mar, 2004: 84, fig. 7). 

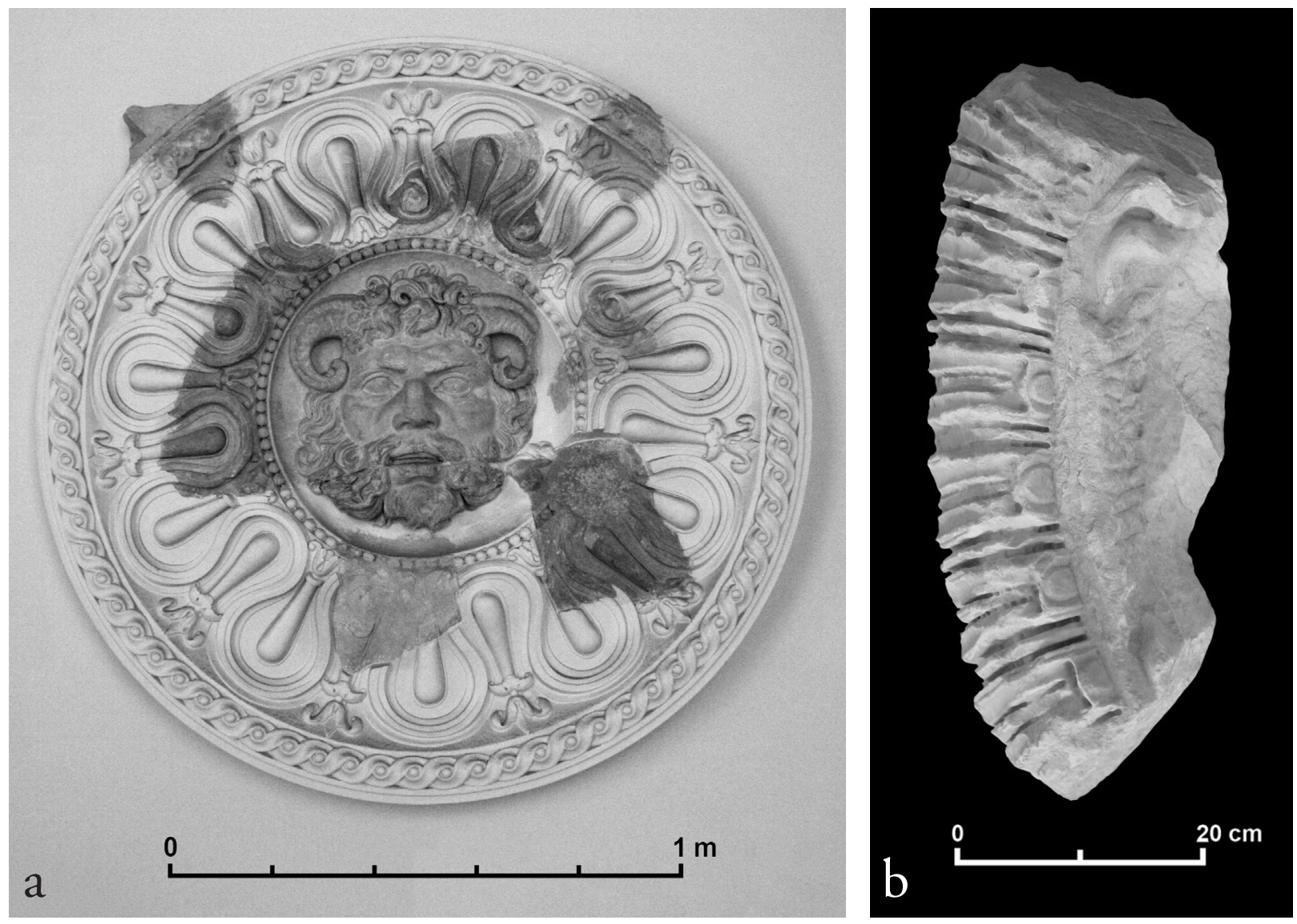

Fig. 4. Fragmentos de clipeos con representación de: a) Júpiter Amón y b) de Medusa (Macias et al., 2007c: 779, fig. 6, 3).
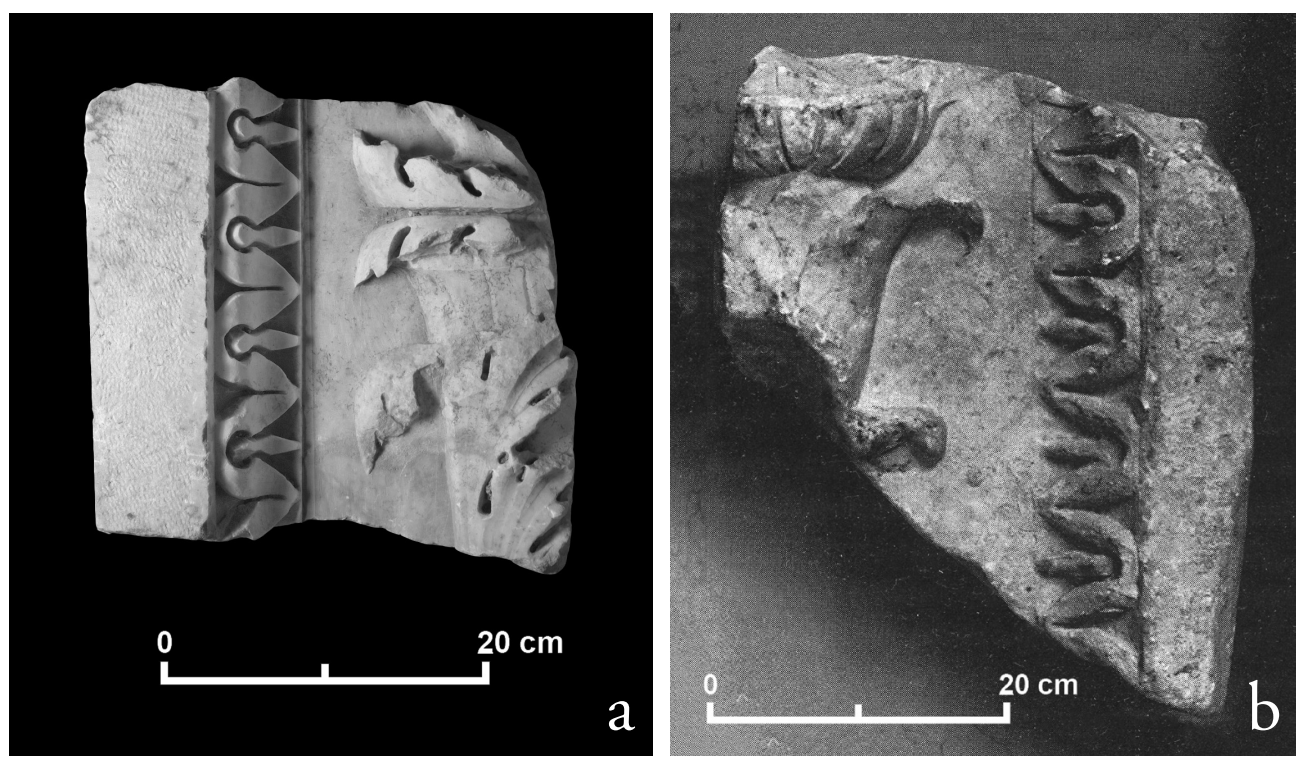

Fig. 5. Fragmentos de placas con candelabros (a: Macias et al., 2007c: 782, fig. 9, 1; b: Pensabene, 1993: 98, n. ${ }^{\circ}$ 96). 
pórtico está confirmada por las cerámicas aparecidas en los rellenos constructivos de la pavimentación exterior al recinto -coetánea a la construcción del muro de fondo del pórtico- por su lado oriental, analizadas por Aquilué (1993: 87-91); y, sobre todo, por los elementos de la decoración arquitectónica, estudiados por Gimeno (1991) y Pensabene (1993). Puesto que se conservan prácticamente todos los componentes de su alzado, tanto de las columnas como del entablamento, es posible llevar a cabo su reconstrucción de un modo bastante fidedigno. A todos estos elementos arquitectónicos cabría añadir varios fragmentos de clípeos decorados con las cabezas de Júpiter Amón y de Me-

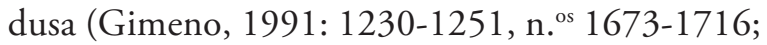
Pensabene, 1993: 89-97, n. ${ }^{\text {os }} 85-93$ ) (Fig. 4) así como de placas decoradas con candelabros (Gime-

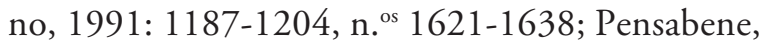
1993: 98-100, n. ${ }^{\text {s }}$ 96-100) (Fig. 5), igualmente fechables en época flavia ${ }^{7}$, producto de hallazgos fortuitos y de diversas intervenciones arqueológicas en la catedral y su entorno inmediato. Aunque se desconoce su ubicación precisa dentro del recinto, existe consenso en atribuirlas al ático del pórtico según el modelo ofrecido por los pórticos del Foro de Augusto, en cuyo ático alternaban clípeos y cariátides (Ungaro, 2011: 43-54) (Fig. 6). Si bien los motivos decorativos varían, el concepto sería similar.

\section{El ático del pórtico de época flavia: restituciones previas}

Hasta la fecha, las únicas reconstrucciones de este ático han venido de la mano de Mar (Fig. 7).

Sin embargo, dicho límite estaría más al s, concretamente en el ábside de la catedral, lugar donde Hauschild (1992: 114, 125, fig. 9) excavó una zanja de las mismas características que la encontrada por Sánchez Real.

Gimeno discrepa de esta datación unitaria, pues fecha los clípeos a finales de época julioclaudia o principios de la flavia y sitúa los candelabros en el s. II d. C. (Gimeno, 1991: 1235 y 1204). En opinión de Koppel (1990: 332339, lám. 32), salvo un ejemplar netamente flavio, el resto de clípeos corresponderían a la época julioclaudia.
La más antigua corresponde a 1993. En ella sitúa los clípeos sobre los ejes de las columnas y en los intercolumnios y los separa mediante candelabros (Mar, 1993: 138-144, 139, fig. 21). La más reciente, de 2009, supone una modificación del esquema anterior, pues sitúa ahora los candelabros sobre los ejes de las columnas y dos clípeos en los intercolumnios separados por un candelabro (Mar y Pensabene, 2009: 375-376, 408, fig. 17). A pesar de su enorme interés, pensamos que ninguna de las dos restituciones es aceptable, puesto que las medidas otorgadas al entre-eje de las columnas y a clípeos y candelabros no se corresponden con las reales.

Ciertamente, cualquier restitución del ático que pretenda llevarse a cabo debe tener presentes una serie de premisas: en primer lugar, la anchura de los clípeos es de 1,60 m. Tomando en consideración varios de los fragmentos empleados en la restitución del clípeo de Júpiter Amón expuesto en el Museu Nacional Arqueològic de Tarragona (Pensabene, 1993: 89-90, n.o 85) (Fig. 4a), esta medida resulta de sumar la anchura de cada uno de los elementos que integran el motivo, esto es, $11 \mathrm{~cm}$ de la trenza exterior -incluidos los tres listeles-, $39 \mathrm{~cm}$ de los meandros -incluida la hilera de perlas- y $60 \mathrm{~cm}$ del emblema ${ }^{8}$. Se trata de la misma medida que presentan los clípeos del pórtico del área sacra de la c/ Sagasta en Mérida (De la Barrera, 2000: 79-80, n. ${ }^{\text {os }} 243,245$ y 247) ${ }^{9}$; en segundo lugar, la anchura de los candelabros es de $60 \mathrm{~cm}$. Esta medida resulta de reproducir por simetría los $30 \mathrm{~cm}$ de anchura que median entre el borde y el eje de uno de los candelabros más completos (Pensabene, 1993: 98, n. ${ }^{\circ}$ 96) (Fig. 5b). La medida coincide igualmente con la de las cariátides del pórtico del citado recinto emeritense (De la Barrera, 2000: 107, n.o 378); en tercer lugar, el diámetro inferior de los fustes

\footnotetext{
8 Gimeno (1991: 1232) les otorga una medida de $1,57 \mathrm{~m}$.

9 Sobre este recinto: Ayerbe et al., 2009a: 753-769. Sobre los elementos arquitectónicos y decorativos del pórtico: Peńa, 2009a: 565 -columnas y entablamento- y Peña, 2009b: 605-607 -clípeos y cariátides-.
} 


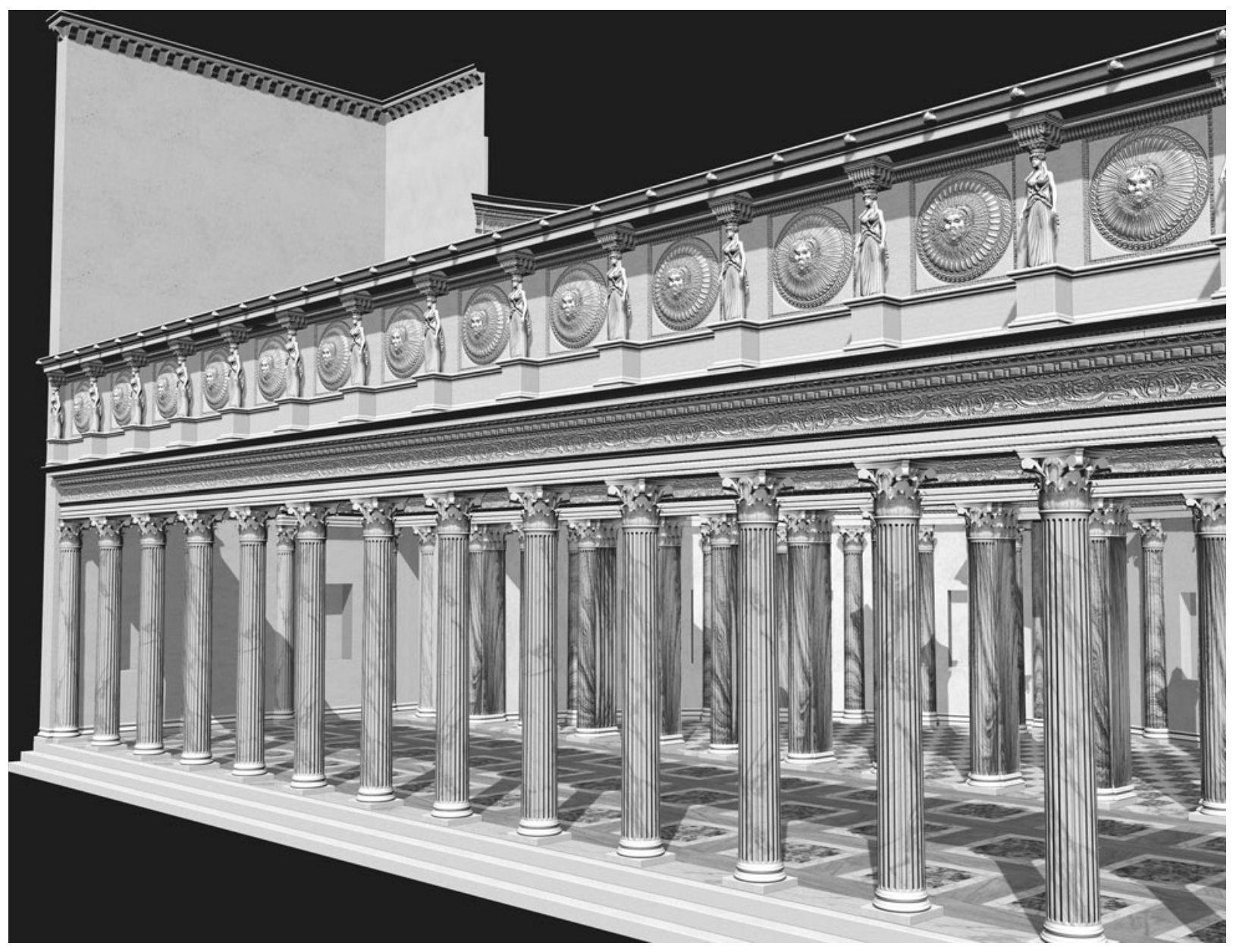

Fig. 6. Reconstrucción 3D del pórtico del Foro de Augusto (Ungaro et al., 2004: 18, fig. 9).

es de $80 \mathrm{~cm}$, según se infiere de medir uno de los fragmentos completos igualmente expuesto en el citado Museo (Pensabene, 1993: 64, n. ${ }^{\circ}$ 48) (Fig. $8)$; por último, la distancia entre el eje de las columnas es de 3,70 m. El cálculo de esta medida se deduce a partir del dibujo realizado por Hauschild del sector noroccidental del muro de fondo del pórtico septentrional (Hauschild, 1983: 102-103, fig. 10) (Fig. 9). Como puede apreciarse hoy en día, en él se abrían ventanas de unos 2,10-2,15 $\mathrm{m}$ de anchura separadas unos 5,25-5,30 m. Disponiendo las columnas delante de las ventanas o entre ellas, resultaría un entre-eje de 7,40 m -ventanas de 2,10 m de anchura separadas 5,30 m-, a todas luces excesivo. En cambio, si las colocáramos delante de las ventanas y entre ellas, resultaría un entre-eje de 3,70 m, más reducido y razonable. Dando por buena esta medida, una disposición más "estética" sería situar dos columnas entre ventanas. En ese caso, quedaría una separación de 80 $\mathrm{cm}$ desde cada ventana a cada eje de columna. Con fustes de $80 \mathrm{~cm}$ de diámetro, el intercolumnio resultante sería de $2,90 \mathrm{~m}$.

Volviendo a las restituciones de Mar, ninguna de ellas se ajusta a tales premisas. Por lo que respecta a la propuesta de 1993, supone un intercolumnio de 3,70 m que, unido a los $70 \mathrm{~cm}$ que otorga al diámetro inferior de los fustes, daría lugar a un entre-eje de columnas de 4,40 m. En virtud de la anchura asignada a clípeos y candelabros, 1,50 m y $60 \mathrm{~cm}$ respectivamente, la propuesta sería asumible, dado que el resultado final sería de 4,20 m, 

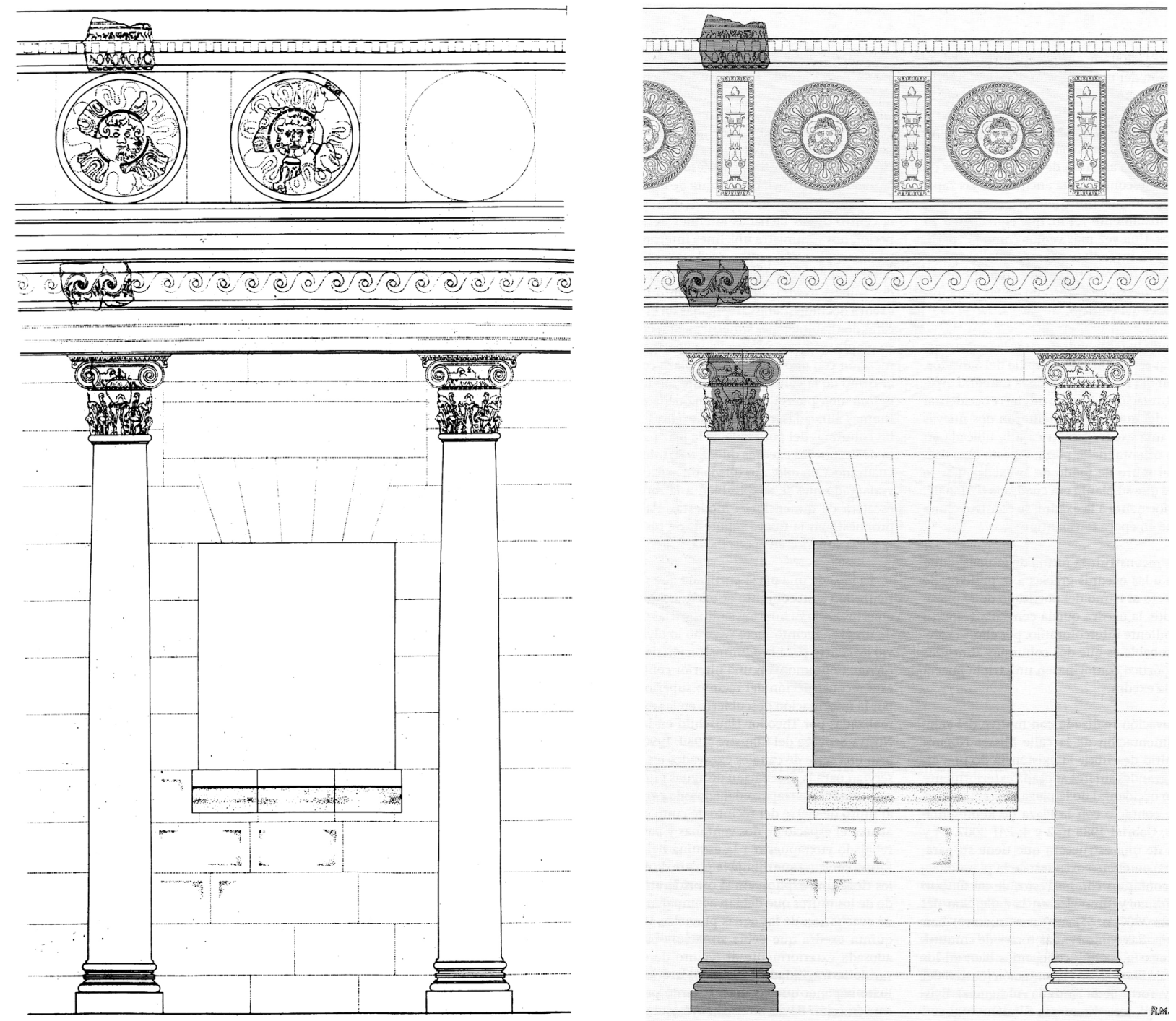

Fig. 7. Reconstrucciones del pórtico del recinto según Mar (1993: 139, fig. 21) y según Mar y Pensabene (2009: 408, fig. 17).

medida inferior a la del entre-eje de las columnas. Sin embargo, puesto que la medida real de este último es de 3,70 m, la restitución no es aceptable. En cuanto a la propuesta de 2009, supone un entre-eje de columnas de 3,76 m. En virtud de la anchura otorgada a clípeos y candelabros, 1,36 m y $48 \mathrm{~cm}$ respectivamente, la propuesta sería asumible, dado que el resultado final sería de 3,68 m, medida inferior a la del entre-eje de las columnas. Sin embargo, puesto que la anchura real de clípeos y candelabros es de 1,60 m y $60 \mathrm{~cm}$ respectivamente, lo que arrojaría un entre-eje de 4,40 m, la restitución tampoco es aceptable ${ }^{10}$.

10 En 2015, Mar ha vuelto nuevamente sobre el asunto, aunque sin formular una nueva propuesta (Mar et al., 2015: 126-128, 112, 113 y 115, figs. 76, 77 y 79). De hecho, mantiene la reconstrucción de 2009, pero recupera las medidas de 1993. La problemática sigue siendo la misma que entonces, esto es, la medida excesiva del entre-eje de las columnas, lo cual invalida la restitución una vez más. 


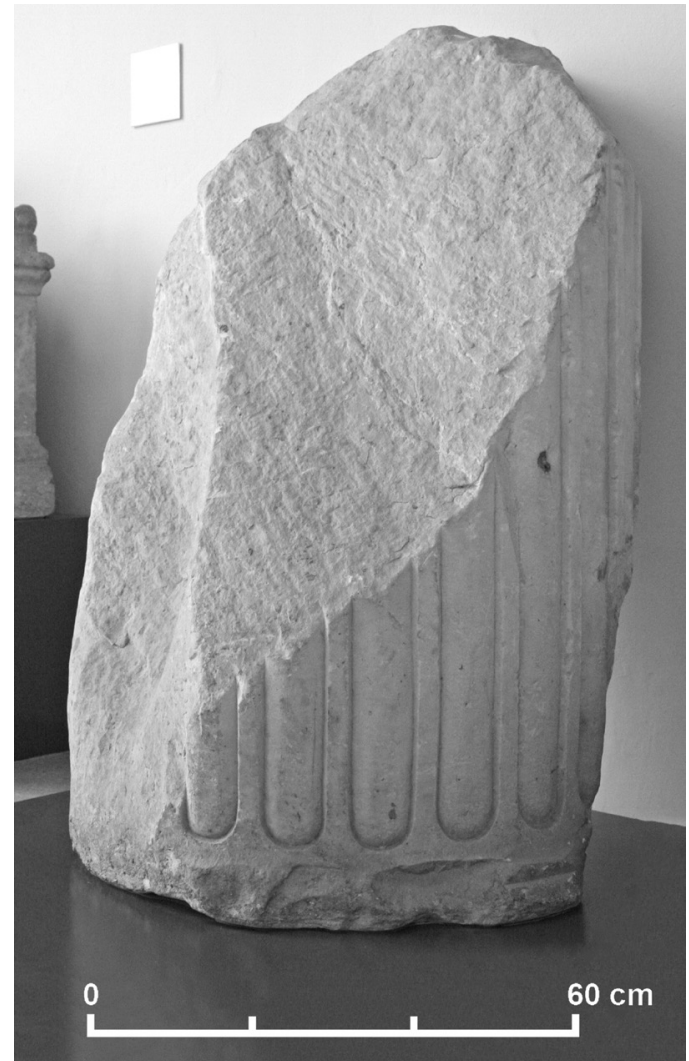

FIG. 8. Fuste con contracanales del pórtico.

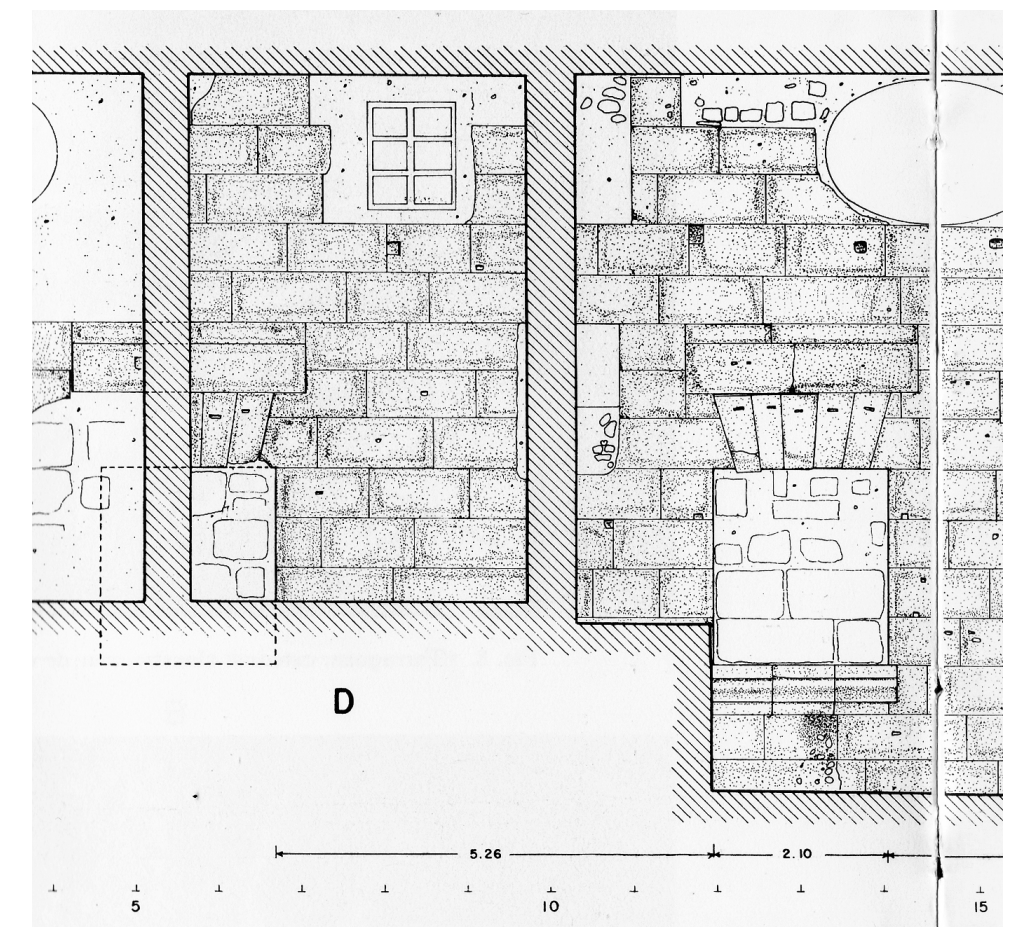

\section{El ático del pórtico de época flavia: nueva restitución, paralelos y posible modelo}

Partiendo de las cuatro premisas anteriormente expuestas y considerando las restituciones de los complejos de Roma, tanto del Foro de Augusto (Ungaro, 2007: 120-121, fig. 144) como del Foro de Trajano (Milella, 2007: 206-207, fig. 285), pensamos que el diseño más adecuado para el ático es el que sitúa los candelabros sobre el eje de las columnas y los clípeos sobre los intercolumnios. La disposición de un único clípeo entre dos candelabros daría lugar a una separación de $75 \mathrm{~cm}$ por lado, a nuestro juicio excesiva. Por ello, hemos planteado otra posibilidad: la disposición de dos candelabros sobre el eje de las columnas y un clípeo sobre el intercolumnio (Fig. 10). Desde el punto de vista estrictamente métrico, la hipótesis es aceptable, pues da lugar a un ático en el que cada una de las placas se distancia $30 \mathrm{~cm}$. La medida es similar a la documentada en el Foro de Augusto (Ungaro, 2004: 23, fig. 5) y en el área sacra de la c/ Sagasta en Mérida (De la Barrera, 2000: plano 2) (Fig. 11), entre 35 y $40 \mathrm{~cm}$ aproximadamente.

Argumento importante a favor de esta restitución es también la existencia en diversas ciudades de la Galia de placas con una decoración similar a la de los clípeos y candelabros de Tarragona. En efecto, en Arlés (Espérandieu, 1925: 112-113, n.o 6731) (Fig. 12), Nyon

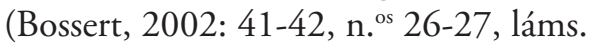
32-33) (Fig. 13) y Avenches (Verzár, 1977: 14-17, n. os 21-25, láms. 11-16; Bossert, 1998: 45-47, n. ${ }^{\circ}$ 19, láms. 1012) (Fig. 14) encontramos placas provistas de un tondo central con imágenes de Júpiter Amón y de otras divinidades, flanqueado por candelabros vegetales. La yuxtaposición de dos de estas placas daría lugar al motivo reconstruido

FIG. 9. Dibujo de Hauschild (1983: 102103, fig. 10) del segmento noroccidental del muro de cierre del pórtico. 

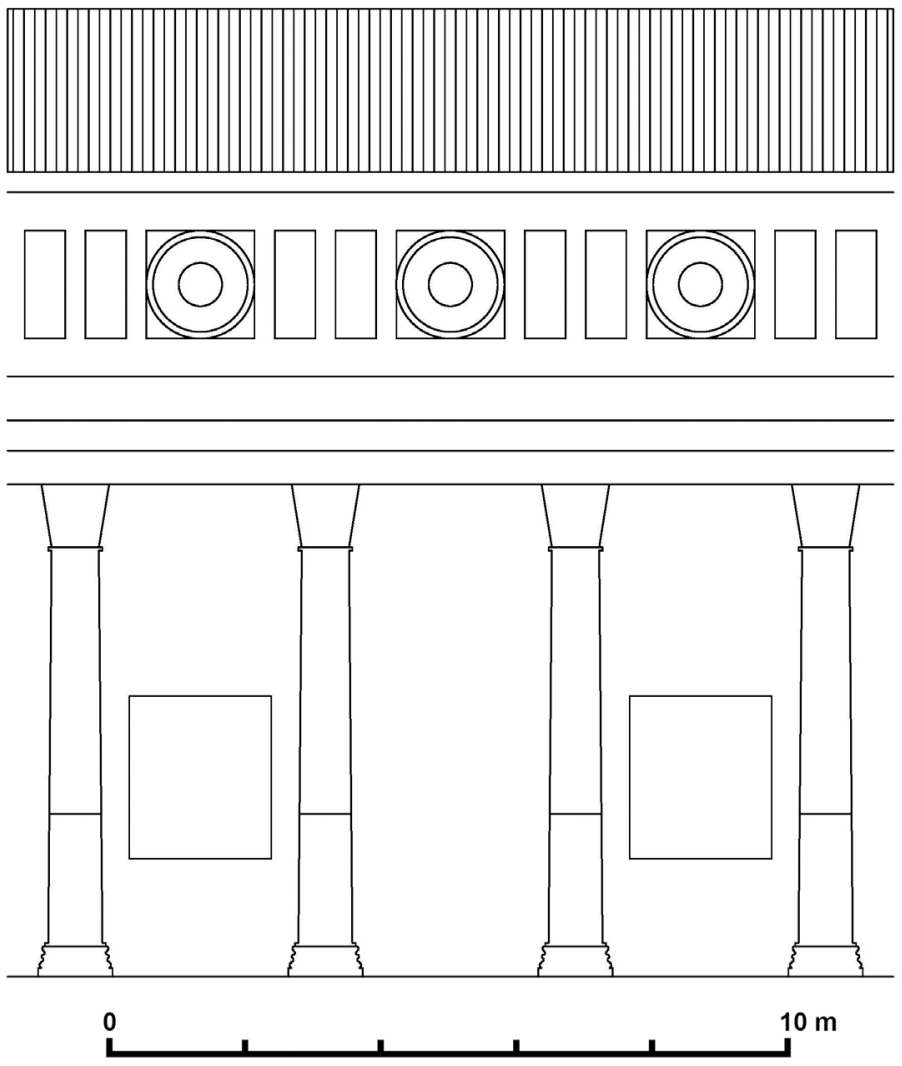

Fig. 10. Nueva propuesta de reconstrucción del pórtico y su ático.

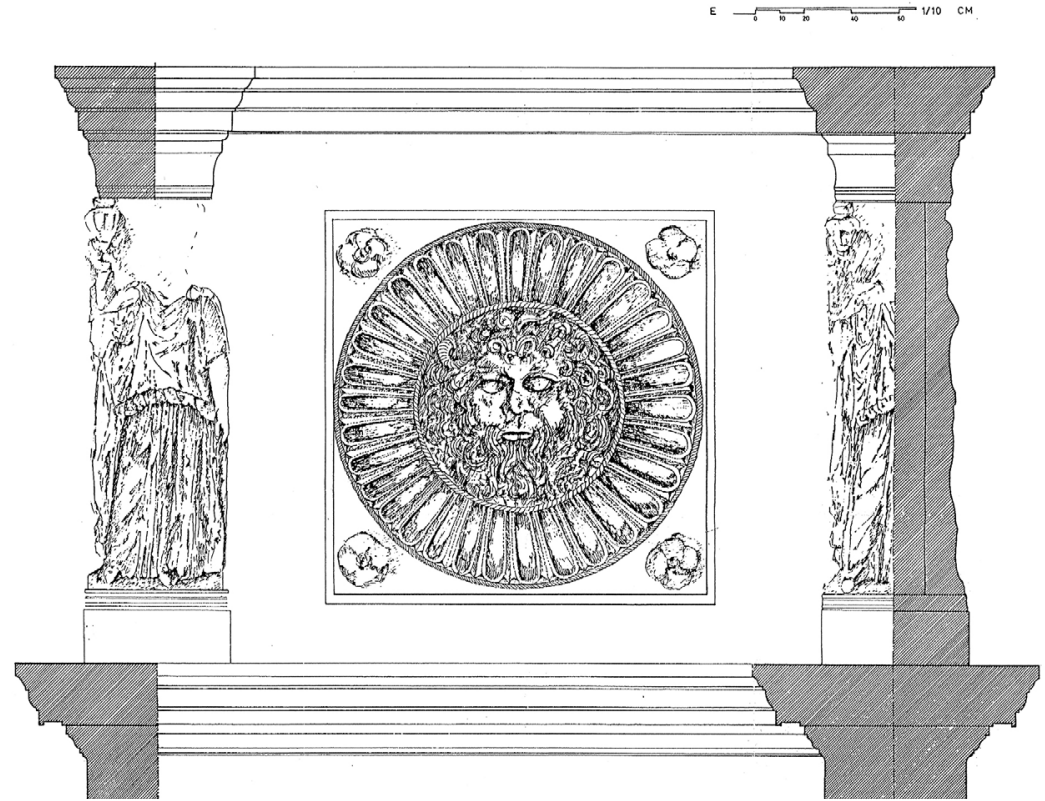

Fig. 11. Reconstrucción del ático del pórtico del área sacra de la cl Sagasta en Mérida (De la Barrera, 2000: plano 2). en Tarragona (Fig. 15). Existen diferentes propuestas sobre la ubicación precisa de todos estos relieves: los de Arlés proceden del denominado forum adiectum, complejo ubicado en el costado occidental del foro, consistente en un área sacra probablemente presidida por un templo y una estrecha plaza de disposición transversal provista de dos exedras laterales (Gros, 1987: 357-361). Según Verzár (1977: 39) las placas corresponderían al podio del templo; los de Nyon proceden del foro ${ }^{11}$, compuesto por un área sacra presidida por un templo y un área pública delimitada por una basílica (Rossi, 1995: 13-50; Brunetti y Henny, 2012: 29-86). Según Bridel (1994: 137, fig. 1) las placas corresponderían a la fachada de esta última; los de Avenches se han puesto en relación con el templo galorromano del santuario de La Grange des Dimes, situado a unos $300 \mathrm{~m}$ al so del foro (Verzár, 1977; Bridel, 2015). Según Verzár (1977: 26, 30, fig. 8) las placas corresponderían al podio del templo, mientras que para Bridel (2015: 51-52, lám. 18) se situarían en el ático del tripórtico adosado al edificio.

A pesar de esta aparente diversidad de ubicación, en virtud de la propuesta que acabamos de presentar para Tarragona, pensamos que lo más probable es que la disposición de todos estos relieves fuera similar: en el caso de Arlés,

11 Aunque las piezas se hallaron en Ginebra y Versoix, su procedencia de Nyon es segura (Bossert, 2002: 41). 


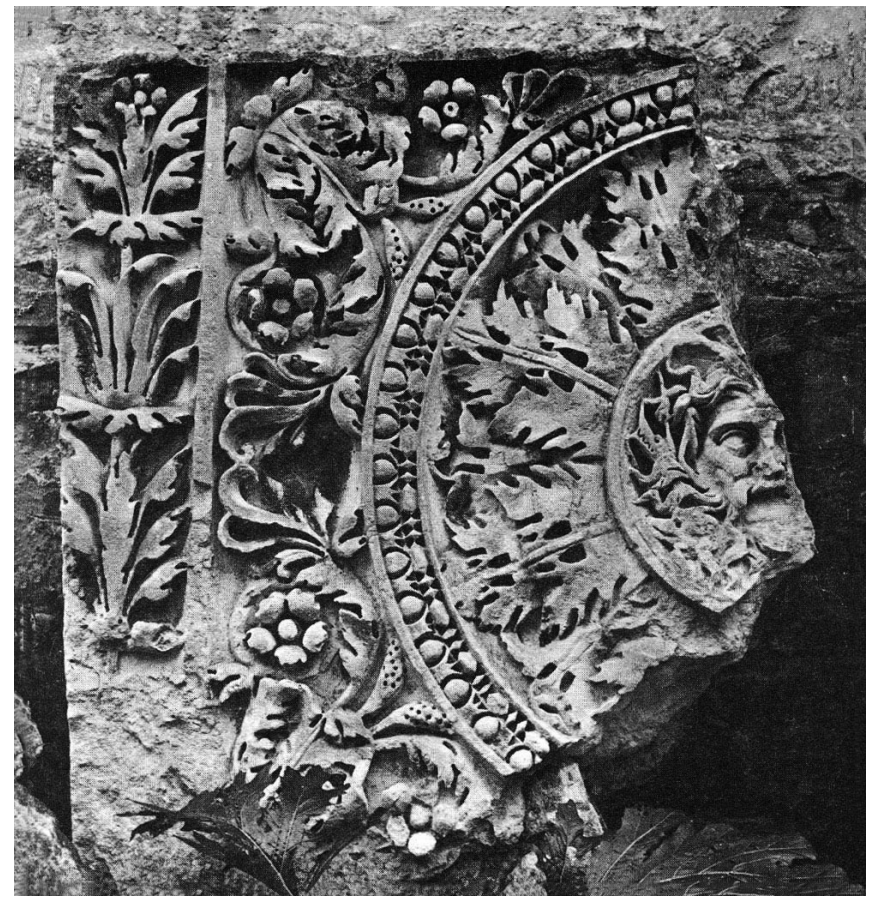

Fig. 12. Placa con tondo y candelabro vegetal de Arlés (Verzár, 1977: lám. 24, 1). Dimensiones: alt. 1,26 m, anch. máx. $1,11 \mathrm{~m}$, grosor $28 \mathrm{~cm}$.

la presencia de una moldura en talón en la parte inferior trasera de uno de los clípeos (Goldbeck, 2015: 97, fig. 138) impide que se adosara al podio del templo y favorece su colocación en el ático del pórtico del área sacra o de la plaza ${ }^{12}$; en el caso de Nyon, su uso como decoración de la fachada de la basílica sería justificable en virtud de la reconstrucción de la fachada de la Basílica Emilia en Roma propuesta por Freyberger, Ertel, Lipps y Bitterer (2007: 518, 510, fig. 18), según la cual el edificio contó con un ático en el que alternaban clípeos con representaciones de orientales ${ }^{13}$. Sin embargo, vistos los ejemplos del Foro de Augusto, de Mérida o de la propia Tarragona, la disposición en un ático en los pórticos del área sacra o del área pública del foro nos parece más probable. El caso de Avenches demanda una atención especial. En nuestra opinión, la supuesta vinculación de las piezas con un templo galorromano,

12 De la misma opinión es Goldbeck (2015: 97-98).

13 Ignoramos los argumentos utilizados por Bridel para defender dicha ubicación, puesto que no nos consta ninguna publicación en la que los haya expuesto. posiblemente dedicado a Mercurio (Bossert et al., 2007: 195-197), resulta completamente insólita por comparación con el resto de casos considerados. Que uno de los clípeos apareciera en las excavaciones de 1905-1906 junto a elementos arquitectónicos de su alzado (Cart, 1907: 10-11, n. ${ }^{4} 4367$, lám. III) no significa que realmente hubiera formado parte del mismo. De hecho, en el área sacra del templo se han encontrado otras piezas cuya atribución al edificio nos parece dudosa: en primer lugar, una basa ática sin plinto con el imoscapo del fuste, aparecida en las excavaciones de 1964 delante de la escalinata del templo, atribuida por Bridel (2015: 142-143, n. ${ }^{\circ}$ 56, fig. 129, lám. 6, 2.1.1.) al pronaos. Estas características, unidas a los dos toros de similar diámetro y a la escocia escasamente desarrollada, son propias de época augústea o, a lo sumo, de las primeras décadas del s. I d. C. (Márquez, 1998: 116-117) ${ }^{14}$. En consecuencia, no parece probable que pueda pertenecer al templo, construido en época tardoflavia o trajanea (Bossert et al., 2007: 174) ${ }^{15}$; y, en segundo lugar, varios fragmentos escultóricos en mármol lunense correspondientes a cinco estatuas imperiales de época tiberiano-caligulea aparecidos en las excavaciones de 2004 en una trinchera que atraviesa el área sacra del templo de NE a so (Bossert et al., 2007: 175-192). Según Bossert, Meylan, Chevalley y Mazur (2007: 176), en un primer momento se situaron al aire libre sobre un basamento ubicado en el extremo nororiental del área sacra y posteriormente pudieron disponerse en el templo. Esta propuesta presenta una objeción fundamental, a saber, que este basamento fue destruido en época vespasianea, como

14 Ejemplos similares los encontramos en las basas de los templos forenses de Mérida y Barcelona, ambos fechados en época augústea (De la Barrera, 2000: 23, n. ${ }^{\circ}$ 1, fig. 7; Gutiérrez Behemerid, 1991: 103, fig. 3).

15 En el templo del cercano santuario de El Cigognier, situado a unos $50 \mathrm{~m}$ al SE del templo del santuario de $L a$ Grange des Dîmes y construido en la misma época (Bridel, 1982: 152-155), las basas áticas responden a una tipología completamente distinta, más habitual en época altoimperial, pues constan de plinto, dos toros de diferente diámetro y escocia desarrollada (Bridel, 1982: 64, lám. 82). 


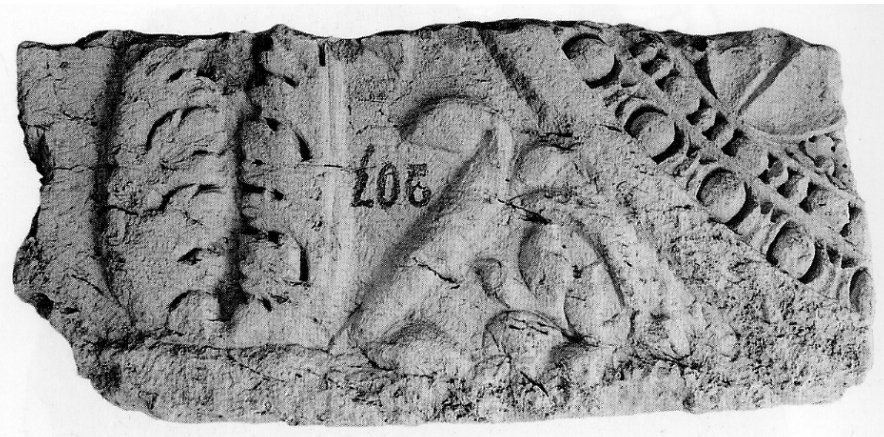

Fig. 13. Placa con tondo y candelabro vegetal de Nyon (Bossert, 2002 . lám. 33, n. 27). Dimensiones: alt. máx. 54 cm, anch. máx. $1,15 \mathrm{~m}$, grosor máx. $46 \mathrm{~cm}$.
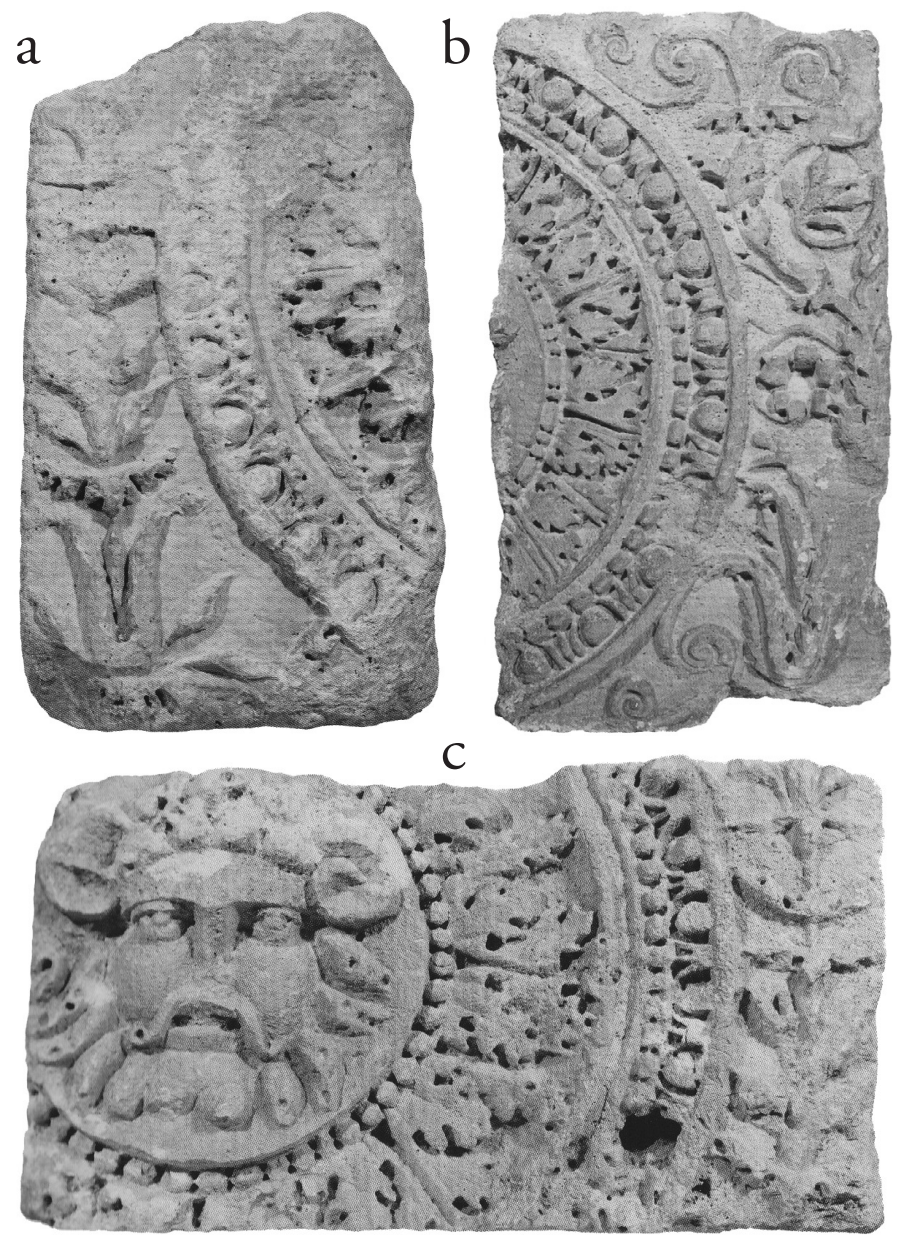

Fig. 14. Placas con tondo y candelabro vegetal de Avenches (Bridel, 2015: 129, fig. 97; 130, fig. 100; 136, fig. 115). Dimensiones: alt. máx. $95 \mathrm{~cm}$, anch. máx. $56 \mathrm{~cm}$, grosor $36 \mathrm{~cm}$ (a); alt. 1,20 m, anch. máx. $67 \mathrm{~cm}$, grosor $41 \mathrm{~cm}$ (b); alt. máx. $56 \mathrm{~cm}$, anch. máx. $1 \mathrm{~m}$, grosor $36 \mathrm{~cm}$ (c). ellos mismos reconocen (Bossert et al., 2007: 171), con lo cual se las privaba del único emplazamiento del santuario que podía albergarlas antes de la construcción del templo. Así las cosas, nuestra impresión es que todas estas piezas se transportaron hasta aquí desde otro lugar para ser reelaboradas por un taller ubicado en las proximidades del templo (Peña, 2009b: 607$, n. 160$)^{16}$. Prueba de su existencia sería el conjunto de elementos lapídeos de diferente naturaleza y enormemente fragmentarios -decoración arquitectónica en caliza, estatuas de mármol blanco- hallado en las citadas excavaciones de 1905-1906 (Cart, 1907: 6), posiblemente interpretable como un depósito de materiales, quizá para convertirlos en $\mathrm{cal}^{17}$. Y prueba de su actividad sería el aserrado del clípeo encontrado para producir una placa de forma rectangular (Verzár, 1977: 14-16, n. ${ }^{\text {os }}$ 21-23, láms. 11-14) ${ }^{18}$. Si estamos en lo cierto, el clípeo habría sido trasladado allí desde otro complejo de la ciudad. Vistos los ejemplos

16 En el caso de la basa, la evidencia arqueológica no contradice la propuesta, pues de ella solo se conoce el lugar de hallazgo, pero no el contexto en que apareció. En cuanto a las estatuas, los autores señalan que se encontraron en niveles de destrucción del s. III d. C. junto a elementos arquitectónicos correspondientes al templo (Bossert et al., 2007: 175). $\mathrm{Al}$ no tener acceso a los informes de excavación, no hemos podido contrastar esta información referente al contexto y datación de dichos niveles. Sin embargo, la destrucción de estatuas imperiales en el s. III d. C. resulta del todo sorprendente, puesto que en estas fechas estaban protegidas por la legislación (Dig. $48,4,6)$. Por esta razón, no juzgamos imposible que las estatuas se hubieran destruido en otro lugar y sus fragmentos se hubieran trasladado hasta el emplazamiento del templo.

17 De la misma opinión es Bossert (1998: 44).

18 Si bien en las excavaciones de 1905-1906 solo se encontró este clípeo (Bridel, 2015: 135-136, n. $\left.{ }^{\text {os }} 39-40\right)$, es de suponer que los otros dos fragmentos sin procedencia albergados en el Museo de Avenches desde mediados del s. xIX (Bridel, 2015: 128130 n $^{\text {os }} 26$ y 29), provistos de un aserrado, forma y tamaño similar, también fueron reelaborados en este mismo lugar. 

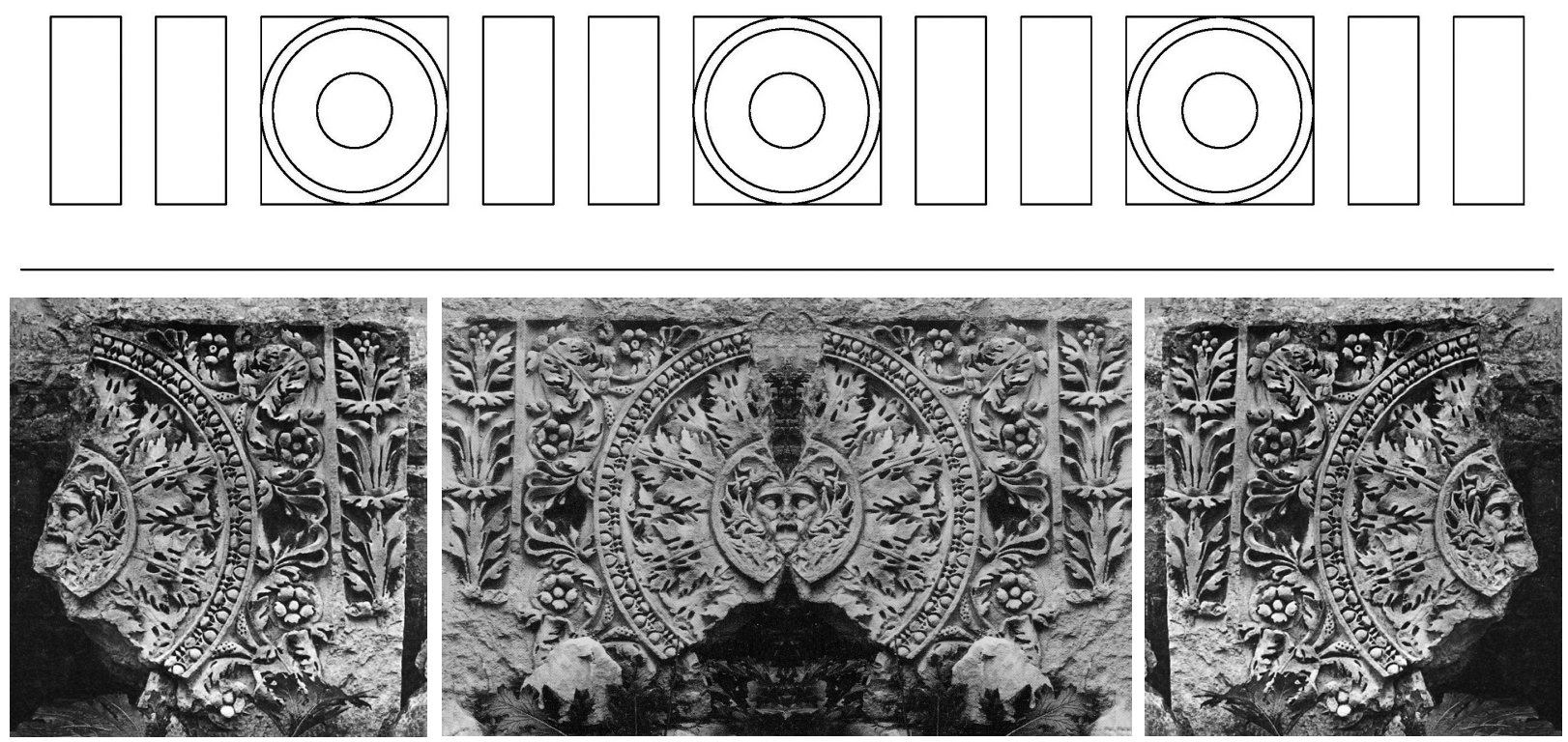

Fig. 15. Propuesta de reconstrucción del ático del pórtico de Tarraco y restitución del motivo a partir de la placa de Arlés.

anteriores y teniendo en cuenta su datación flavia (Verzár, 1977: 39-41; 1995: 19-25; Bossert, 1998: 52-53), lo más probable es que proceda del foro renovado en época tardoflavia-trajanea (Bossert y Fuchs, 1989: 38), situado en un ático en los pórticos del área sacra o en los de la plaza ${ }^{19}$. La citada basa con imoscapo y los fragmentos del ciclo estatuario tiberiano-caliguleo podrían compartir la misma procedencia: la basa correspondería al templo forense $e^{20}$, mientras que las estatuas formarían parte

19 Sobre la configuración arquitectónica del foro en esta fase: Bossert y Fuchs, 1989: 24-35, lám. 22. En caso de que el clípeo realmente no procediera del foro, otra posible ubicación sería el santuario de El Cigognier -cuya planta se asemeja notablemente a la del recinto de Tarragona-, tanto por su coetaneidad como por el hecho de que sobre la columnata del pórtico discurría un alto muro similar a un ático (Bridel, 1982: 128, lám. 83).

20 Ante la ausencia de elementos arquitectónicos pertenecientes al edificio (Bossert y Fuchs, 1989: 28), la hipótesis resulta plausible. La cronología augústea o tiberiana de la pieza no constituye ningún obstáculo para dicha atribución puesto que no existe evidencia alguna de que el templo, como el resto del foro, fuera reformado en época tardoflavia-trajanea. Antes bien, cabe pensar que se mantuvo sin cambios desde su construcción, fechada en época tiberiana (Bossert y Fuchs, 1989: 38). Estaríamos, por tanto, ante un de un ciclo estatuario imperial de la misma época aparecido en las excavaciones del foro en 1972 (Bossert y Kaspar, 1974) ${ }^{21}$.

Aunque el esquema decorativo del ático está inspirado en el ático del Foro de Augusto, la sustitución de cariátides por candelabros invita a pensar en otro modelo para Tarragona y el resto de ejemplos considerados. Al respecto, cabe plantear dos posibilidades: la primera, que deriven de un modelo común de Roma. En este sentido, dada la cronología flavia de todos ellos ${ }^{22}$, podríamos tomar en consideración el

caso similar al del foro augústeo de Mérida, íntegramente reconstruido en mármol en época flavia a excepción del templo, que mantuvo su aspecto original en granito estucado (Ayerbe et al., 2009b: 820). Sobre el edificio emeritense cf. Álvarez y Nogales, 2003.

${ }^{21}$ En el caso de que realmente los clípeos hubieran formado parte de la decoración del templo de La Grange des Dîmes, podría aceptarse la propuesta de Bridel de ubicarlos en el ático del tripórtico adosado al edificio. En cambio, la colocación en el podio del templo, sugerida por Verzár, debería ser descartada puesto que, como señaló Bossert según indicación de Bridel, el podio estuvo revestido por placas lisas de arenisca, una de las cuales se encontraba aún in situ (Bossert, 1998, 56, n. 55).

22 Sobre Arlés: Kleinwächter, 2001: 158-159; Peña, 2009a: 576-577; Goldbeck, 2015: 97. En cambio, Gros 
Templum Pacis. Ciertamente, la evidencia conocida de este complejo (Meneghini et al., 2009: 197-199; Pinna, 2014) no ofrece testimonio alguno ni de clípeos ni de candelabros, lo cual podría ser un argumento en contra de esta opción. Sin embargo, el pórtico sí que dispuso de un ático, como bien ha argumentado Tucci (2009: 158-159; 2017: 89-101), en el que pudieron figurar estos elementos $^{23}$ (Fig. 16); y la segunda, que Tarragona fuera el modelo en el que se inspiraron las ciudades de la Galia. Esta opción no resulta en absoluto descabellada si aceptamos que el conjunto de construcciones de la acrópolis formaba parte de un proyecto imperial ${ }^{24}$.

(1987: 357-361; 2008, 48-50) los fecha en época tiberiana o claudia. Sobre Nyon $c f$. Bossert, 2002: 42; Peña, 2009a: 577. En cambio, Rossi y Bridel los consideran más antiguos pues corresponden a la segunda fase constructiva del foro, fechable por el primero en época tiberiano-claudia (Rossi, 1995: 24) y por el segundo en época claudio-neroniana (Bridel, 1994: 149). Sobre Avenches: Verzár, 1977: 39-41; Verzár, 1995: 1925; Bossert, 1998: 52-53.

23 Meneghini, Corsaro y Pinna (2009: 191, fig. 1) son de otra opinión, pues defienden la
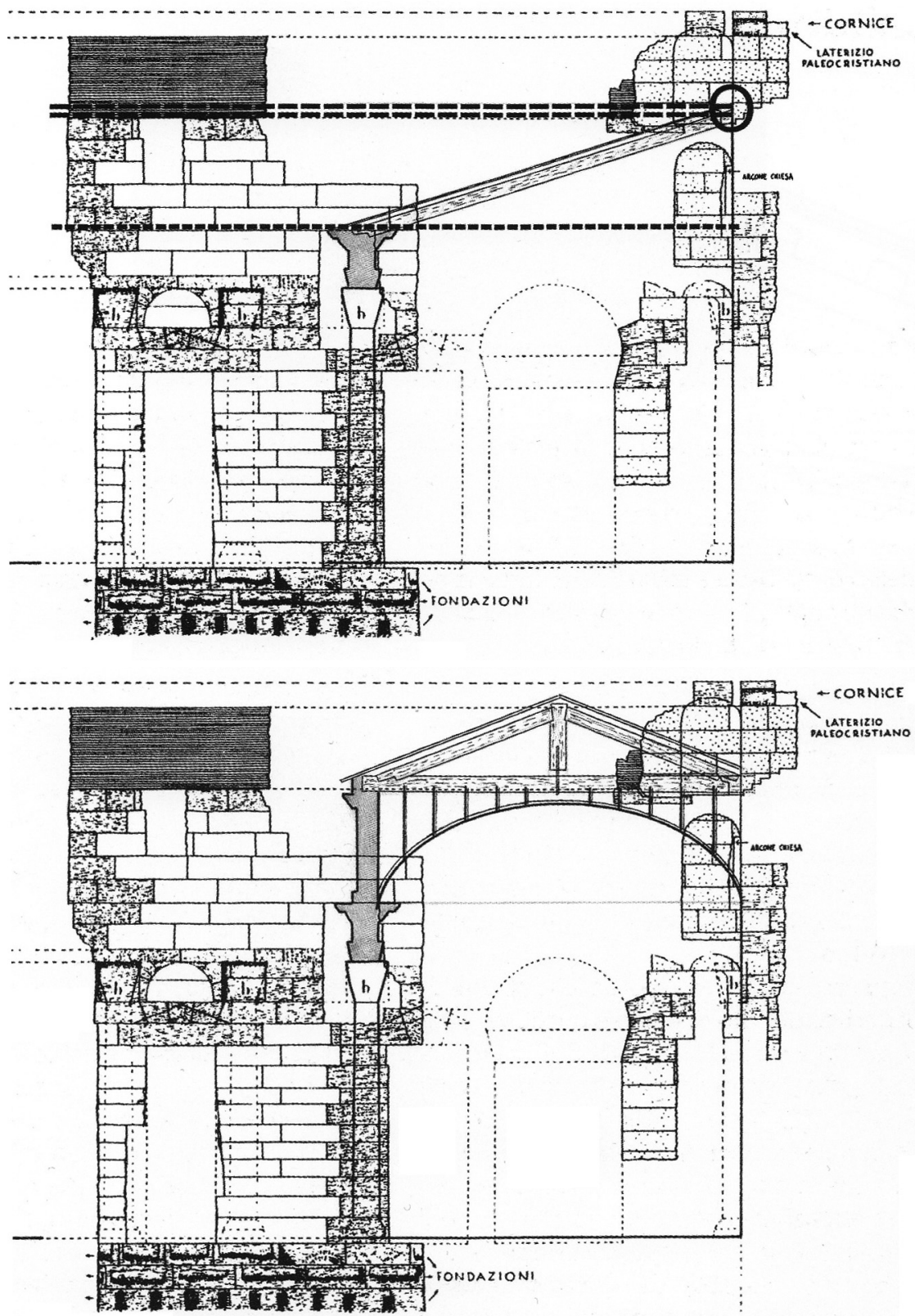

FIG. 16. Reconstrucciones del pórtico del Templum Pacis sin y con ático (Tucci, 2009: 159, figs. 1 y 2). existencia de un pórtico sin ático con cubierta a una sola vertiente. En publicaciones posteriores, Meneghini (2014) rechaza la hipótesis de Tucci, mientras que Pinna (2014) ni siquiera la menciona.

24 En cambio, otros investigadores (Pensabene, 1996: 210-211; Ruiz de Arbulo, 1998: 53-54) han considerado el conjunto como un proyecto financiado por las élites provinciales o bien el resultado de una financiación mixta que reunía a la administración provincial, las
A favor de ello se manifiestan la magnitud del mismo, unas 12 ha (Macias et al., 2007a: 40) ${ }^{25}$ y su ejecución por parte de un avezado arquitecto -como se élites provinciales y la propia Tarraco (Mar y Pensabene, 2009: 368).

25 Para la comparación de sus dimensiones respecto a otros grandes complejos edilicios del Imperio: Ted'A, 1989: 188, fig. 28. 
advierte del perfecto encaje del conjunto dentro de las murallas-; la colosalidad de los edificios del recinto de culto, tanto de la sala axial (Mar y Pensabene, 2009: 378-379) como del templo dedicado a Divus Augustus (Pensabene y Mar, 2010: 255-277), cuya construcción fue autorizada por Tiberio (Tac. Ann. I, 78) y su restauración emprendida por Adriano (Spart. Hadr. XII, 3); el empleo sistemático del mármol lunense ${ }^{26}, y$, por último, la presencia de talleres vinculados a Roma o incluso procedentes de ella (Pensabene, 1996: 202). Todo ello en la capital de la provincia más grande del Imperio (Oscáriz, 2009: 324).

De las dos posibilidades consideradas, pensamos que la opción más probable es la primera, esto es, que el modelo fuera el ático del pórtico del Templum Pacis, a favor de lo cual podría esgrimirse también la semejanza de la planta del recinto tarraconense con la del complejo de Roma. Sin embargo, ante la falta de evidencias materiales que sustenten esta hipótesis, por el momento habrá que dejar la cuestión abierta.

\section{Bibliografía}

Álvarez, A.; Macias, J. M.; Muñoz, A.; Pitarch, A.; Teixell, I. y Menchón, J. (2012): "The marmora used in the imperial cult area of Tarraco (Hispania Citerior)”. En Gutiérrez, A.; Lapuente, P. y RodÀ, I. (eds.): Interdisciplinary studies of ancient stone. Tarragona: ICAC, pp. 196-203.

Álvarez, J. M. y Nogales, T. (2003): Forum Coloniae Augustae Emeritae. 'Templo de Diana'. Mérida: Asamblea de Extremadura.

Aquilué, X. (1993): La seu del Col.legi d'Arquitectes. Una intervenció arqueològica en el centre històric de Tarragona. Tarragona: Col-legi d'Arquitectes de Catalunya.

Ayerbe, R.; Barrientos, T. y Palma, F. (2009a): “Arquitectura, configuración y restitución de los recintos monumentales". En Ayerbe, R.; Barrientos, T. y Palma, F. (eds.): El foro de Augusta Emerita. Génesis y evolución de sus recintos monumentales. Mérida: csic, pp. 667-806.

26 Así se deduce de las inspecciones de visu, confirmadas plenamente por las analíticas realizadas a algunos de los materiales recuperados en las excavaciones de Macias, Menchón, Muñoz y Teixell (Álvarez et al., 2012: 201).
Ayerbe, R.; Barrientos, T. y Palma, F. (2009b): "Génesis y evolución del foro de Augusta Emerita”. En Ayerbe, R.; Barrientos, T. y Palma, F. (eds.): El foro de Augusta Emerita. Génesis y evolución de sus recintos monumentales. Mérida: CSIC, pp. 807-831.

Bossert, M. (1998): Die figürlichen Reliefs von Aventicum. Lausanne: Cahiers d'Archéologie Romande.

Bossert, M. (2002): Die figürlichen Skulpturen von Colonia Julia Equestris. Lausanne: Cahiers d'Archéologie Romande.

Bossert, M. y Fuchs, M. (1989): "De l'ancien sur le forum d'Avenches", Bulletin de l'Association Pro Aventico, 31, pp. 12-105.

Bossert, M. y Kaspar, D. (1974): "Eine iulisch-claudische Kaiserkultgruppe in Avenches”, Bulletin de l'Association pro Aventico, 22, pp. 17-26.

Bossert, M.; Meylan, M.-F.; Chevalley, C. y Mazur, A. (2007): "Aventicum. Présence impériale dans les sanctuaires de la Grange des Dîmes et de Derrière la Tour", Bulletin de l'Association Pro Aventico, 49, pp. 159-205.

Bridel, P. (1982): Aventicum III. Le sanctuaire du Cigognier. Lausanne: Cahiers d'Archéologie Romande.

Bridel, P. (1994): "Le programme architectural du forum de Nyon (Colonia Julia Equestris) et les étapes de son dévelopment". En Actas XIV Congreso Internacional de Arqueología Clásica. La ciudad en el mundo romano. Tarragona, vol. 1, pp. 137-151.

Bridel, P. (2015): Le sanctuaire de la Grange des Dîmes à Avenches. Les temples et le péribole-Étude des architectures. Lausanne: Cahiers d'Archéologie Romande.

Brunetti, C. y Henny, C. (2012): Recherches sur l'area publica de la Colonia Iulia Equestris (Nyon, canton de Vaud). Lausanne: Cahiers d'Archéologie Romande.

Burnett, A.; Amandry, M. y Ripollès, P. P. (1992): Roman Provincial Coinage I. London: BMP.

Cart, W. (1907): "Le Temple Gallo-Romain de la 'Grange du Dîme' à Avenches”, Bulletin de l'Association Pro Aventico, 9, pp. 3-23.

Casas, A.; Cosentino, P. L.; Díaz, Y.; Fiandaca, G.; García, E.; Himi, M.; Lafuente, M.; Martorana, R.; Macias, J. M.; Menchón, J.; Muñoz, A.; Sala, R. y Teixell, I. (2009): "Integrated archaeological and geophysical survey for searching the Roman temple of Augustus in Tarragona, Spain”. En Scienza e patrimonio culturale nel Mediterraneo. Palermo, pp. 277-283.

De la BArrera, J. L. (2000): La decoración arquitectónica de los foros de Augusta Emerita. Roma: L'Erma di Bretschneider. 
Dupré, X. y Carreté, J. M. (1993): La “Antiga Audiència". Un acceso al Foro Provincial de Tarraco. Tarragona: Autoridad Portuaria.

Dupré, X.; Massó, J.; Palanques, M. L. y Verduchi, P. A. (1988): El circ romà de Tarragona, I. Les voltes de Sant Ermenegild. Barcelona: Generalitat de Catalunya.

Espérandieu, E. (1925): Recueil général des bas-reliefs de la Gaule romaine. Paris: Imprimerie Nationale, vol. 9 .

Freyberger, K. S.; Ertel, C.; Lipps, J. y Bitterer, T. (2007): "Neue Forschungen zur Basilica Aemilia auf dem Forum Romanum. Ein Vorbericht", Römische Mitteilungen, 113, pp. 493-552.

Gimeno, J. (1991): Estudios de arquitectura y urbanismo en las ciudades romanas del nordeste de Hispania. Madrid: UCM, 2 vols.

Goldbeck, V. (2015): Fora Augusta. Das Augustusforum und seine Rezeption im Westen des Imperium Romanum. Regensburg: Schnell \& Steiner.

Gros, P. (1987): "Un programme augustéen: le centre monumental de la colonie d'Arles", Jahrbuch des Deutschen Archäologischen Instituts, 102, pp. 339-363.

Gros, P. (2008): La Gaule Narbonnaise. De la conquête romaine au IIIe siècle apr. J.-C. Paris: Picard.

Güell, M.; Peña, I.; Tobías, O. y Tubilla, M. (1993): "La restitución arquitectónica de la plaza de representación (el denominado 'Foro Provincial')". En MAR, R. (ed.): Els monuments provincials de Tàrraco. Noves aportacions al seu coneixement. Tarragona: URV, pp. 157-190.

Gutiérrez Behemerid, M. A. (1991): "El templo romano de Barcino. Análisis de la decoración arquitectónica", Cuadernos de Arquitectura Romana, 1, pp. 95-105.

Hauschild, T. (1972-1974): "Römische Konstruktionen auf der oberen Stadtterrasse des antiken Tarraco", Archivo Español de Arqueología, 45-47, pp. 3-44.

Hauschild, T. (1983): "Construccions romanes a la terrassa superior de l'antiga Tarragona”. En HausCHILD, T.: Arquitectura romana de Tarragona. Tarragona: Ayto. de Tarragona, pp. 87-129.

Hauschild, T. (1992): "Los hallazgos romanos de mármol en la Parte Alta de Tarragona”, Butlletí Arqueològic, 14, pp. 107-135.

HausChild, T. (2009): "Algunas observaciones sobre la construcción de la sala-aula situada detrás de la Catedral de Tarragona", Butlletí Arqueologgic, 31, pp. 313-344.

Kleinwächter, C. (2001): "Tiberius in Arles?". En Bergemann, J. (ed.): Wissenschaft mit Enthusiasmus.
Beiträge zu antiken Bildnissen und zur historischen Landeskunde Klaus Fittschen gewidmet. Rahden: Leidorf, pp. 145-166.

Koppel, E. (1990): "Relieves arquitectónicos de Tarragona”. En Trillmich, W. y Zanker, P. (eds.): Stadtbild und Ideologie. Die Monumentalisierung hispanischer Städte zwischen Republik und Kaiserzeit. München: Bayerische Akademie der Wissenschaften, pp. 327-340.

Macias, J. M.; Fiz, I.; Piñol, L.; Miró, M. T. y GuITART, J. (dirs.) (2007a): Planimetria arqueologgica de Tarraco. Tarragona: ICAC, 2 vols.

Macias, J. M.; Menchón, J.; Muñoz, A. y Teixell, I. (2007b): "L'Arqueologia de la Catedral de Tarragona. La memòria de les pedres". En La catedral de Tarragona. In Sede, 10 anys del Pla Director de Restauració. Tarragona: Arola edit., pp. 151-213.

Macias, J. M.; Menchón, J.; Muñoz, A. y Teixell, I. (2007c): "Excavaciones en la catedral de Tarragona y su entorno: avances y retrocesos en la investigación sobre el culto imperial". En Nogales, T. y GonZÁLEZ, J. (eds.): Culto imperial: política y poder. Roma: L'Erma di Bretschneider, pp. 765-787.

Macias, J. M.; Menchón, J.; Muñoz, A. y Teixell, I. (2010a): "La construcción del recinto imperial de Tarraco (provincia Hispania Citerior)", Butlletí Arqueològic, 32, pp. 423-479.

Macias, J. M.; Menchón, J.; Muñoz, A. y Teixell, I. (2010b): "La acrópolis de Tarraco y la implantación urbana del culto imperial en la capital de la Hispania Citerior", Bollettino di Arqueologia on line, 1, A/ A8/4, pp. 50-66.

Macias, J. M.; Muñoz, A.; Peña, A.; Ramon, M. y Teixell, I. (2012): Praesidium, Templum et Ecclesiae. Les intervencions arqueològiques a la catedral de Tarragona 2010-2011. Tarragona: ICAC.

Macias, J. M.; Muñoz, A.; Peña, A. y Teixell, I. (2014): "El templo de Augusto en Tarraco: últimas excavaciones y hallazgos". En Álvarez, J. M.; Nogales, T. y RodÀ, I. (eds.): Centro y periferia en el mundo clásico, vol. 2. Mérida: MNAR, pp. 1539-1543.

Macias, J. M.; Muñoz, A. y Teixell, I. (2010-2011): "Arqueologia a la nau central de la Catedral de Tarragona”, Tribuna d'Arqueologia, 2010-2011, pp. 151-173.

Macias, J. M.; Muñoz, A.; Teixell, I. y Menchón, J. (2011): "Nuevos elementos escultóricos del recinto de culto del Concilium Provinciae Hispaniae Citerioris (Tarraco, Hispania Citerior)". En Nogales, T. y RodÀ, I. (eds.): Roma y las provincias: modelo y 
difusión. Roma: L’Erma di Bretschneider, vol. 2, pp. 873-886.

Mar, R. (1993): "El recinto de culto imperial de Tarraco y la arquitectura flavia". En MAR, R. (ed.): Els monuments provincials de Tàrraco. Noves aportacions al seu coneixement. Tarragona: URV, pp. 107-156.

Mar, R. y Pensabene, P. (2009): "Financiación de la edilicia pública y cálculo de los costes del material lapídeo: el caso del foro superior de Tarraco", Butlletí Arqueologic, 31, pp. 345-409.

Mar, R. y Pensabene, P. (2010): "Finanziamento dell'edilizia pubblica e calcolo dei costi dei materiali lapidei: il caso del foro superiore di Tarraco". En Camporeale, S.; Desalles, H. y Pizzo, A. (eds.): Arqueología de la construcción II. Los procesos constructivos en el mundo romano: Italia y provincias orientales. Madrid: CsIC, pp. 509-537.

Mar, R.; Ruiz de Arbulo, J.; Vivó, D. y Beltrán-CaBallero, J. A. (2012): Tarraco. Arquitectura y urbanismo de una capital provincial romana. De la Tarragona ibérica a la construcción del templo de Augusto. Tarragona: URV.

Mar, R.; Ruiz de Arbulo, J.; Vivó, D.; Beltrán-Caballero, J. A. y Gris, F. (2015): Tarraco. Arquitectura y urbanismo de una capital provincial romana. La ciudad imperial. Tarragona: URV.

Márquez, C. (1998): La decoración arquitectónica de Colonia Patricia. Córdoba: uco.

Meneghini, R. (2014): "L'architettura del Templum Pacis". En Meneghini, R. y Rea, R. (eds.): La biblioteca infinita. I luoghi del sapere nel mondo antico. Milano: Electa, pp. 284-299.

Meneghini, R.; Corsaro, A. y Pinna, B. (2009): "Il Templum Pacis alla luce dei recenti scavi". En Coarelli, F. (ed.): Divus Vespasianus. Il bimillenario dei Flavi. Milano: Electa, pp. 190-201.

Milella, M. (2007): "Il Foro di Traiano". En Ungaro, L. (ed.): Il Museo dei Fori Imperiali nei Mercati di Traiano. Milano: Electa, pp. 192-211.

Miró, M. T. (2017): "El circ, un edifici d'espectacles com a element vertebrador de l'urbanisme de Tàrraco: 35 anys de recerques". En López, J. (ed.): La glòria del circ. Curses de carros i competicions circenses. In memoriam X. Dupré i Raventós. Tarragona: Fund. Privada Mútua Catalana, pp. 219-230.

OsCÁrIz, P. (2009): “Organización administrativa y territorial de las provincias hispanas durante el Alto Imperio". En Andreu, J.; Cabrero, J. y RodÀ, I. (eds.): Hispaniae: las provincias hispanas en el mundo romano. Tarragona: ICAC, pp. 323-338.
Pensabene, P. (1993): "La decorazione architettonica dei monumenti provinciali di Tarraco". En Mar, R. (ed.): Els monuments provincials de Tàrraco. Noves aportacions al seu coneixement. Tarragona: URV, pp. 25-105.

Pensabene, P. (1996): "Classi dirigenti, programmi decorativi, culto imperiale: il caso di Tarraco". En León, P. (ed.): Colonia Patricia Corduba. Una reflexión arqueológica. Sevilla: Junta de Andalucía, pp. 197-219.

Pensabene, P. y Mar, R. (2004): “Dos frisos marmóreos en la Acrópolis de Tarraco, el Templo de Augusto y el complejo provincial de culto imperial". En RUIZ DE Arbulo, J. (ed.): Simulacra Romae. Roma y las capitales provinciales del Occidente Europeo. Tarragona: Edic. El Mèdol, pp. 73-86.

Pensabene, P. y Mar, R. (2010): "Il tempio di Augusto a Tarraco. Gigantismo e marmo lunense nei luoghi di culto imperiale in Hispania e Gallia", Archeologia Classica, 61, pp. 243-307.

Peña, A. (2009a): "La decoración arquitectónica". En Ayerbe, R.; Barrientos, T. y Palma, F. (eds.): El foro de Augusta Emerita. Génesis y evolución de sus recintos monumentales. Mérida: CSIC, pp. 525-582.

Peña, A. (2009b): "La decoración escultórica". En Ayerbe, R.; Barrientos, T. y Palma, F. (eds.): El foro de Augusta Emerita. Génesis y evolución de sus recintos monumentales. Mérida: Csic, pp. 583-621.

Peña, A.; Gorostidi, D.; Macias, J. M.; Muñoz, A.; RodÀ, I. y Teixell, I. (2015): "Más datos sobre el templo del Divus Augustus de Tarraco: a propósito de una nueva inscripción”. En López, J. (ed.): August $i$ les provincies occidentals. 2000 aniversari de la mort d'August. Tarragona: Fund. Privada Mútua Catalana, vol. II, pp. 181-189.

Pinna, B. (2014): "I portici e il muro di delimitazione settentrionale”. En Meneghini, R. y Rea, R. (eds.): La biblioteca infinita. I luoghi del sapere nel mondo antico. Milano: Electa, pp. 300-306.

Pociña, C. A. y Remolì, J. A. (2000): "La Plaza de Representación de Tarraco: intervenciones arqueológicas en la Plaza del Fòrum y la Calle d'en Compte". En Ruiz De Arbulo, J. (ed.): Tàrraco 99. Arqueologia d'una capital provincial romana. Tarragona: URV, pp. 27-45.

Rossi, F. (1995): L'area sacra du forum de Nyon et ses abords. Lausanne: Cahiers d'Archéologie Romande.

Ruiz de Arbulo, J. (1998): "Tarraco. Escenografía de poder, administración y justicia en una capital provincial romana (ss. II a. C.-II d. C.)", Empúries, 51, pp. 31-61. 
Ruiz de Arbulo, J. y Mar, R. (2001): "El circo de Tarraco. Un monumento provincial". En El circo en la Hispania romana. Mérida: Ministerio de Educación, Cultura y Deporte, pp. 141-154.

SÁnchez Real, J. (1969): "Exploración arqueológica en el jardín de la Catedral de Tarragona", Madrider Mitteilungen, 10, pp. 276-295.

Ted'A (1989): "El Foro Provincial de Tarraco, un complejo arquitectónico de época flavia”, Archivo Español de Arqueología, 62, pp. 141-191.

Tucci, P. L. (2009): "Nuove osservazioni sull'architettura del Templum Pacis". En Coarelli, F. (ed.): Divus Vespasianus. Il bimillenario dei Flavi. Milano: Electa, pp. 158-167.

Tucci, P. L. (2017): The Temple of Peace at Rome, vol. 1. Cambridge: cup.

Ungaro, L. (2004): "La decorazione architettonica del Foro di Augusto a Roma”. En Ramallo, S. (ed.): La decoración arquitectónica en las ciudades romanas de Occidente. Murcia: umu, pp. 17-35.
Ungaro, L. (2007): "Il Foro di Augusto". En Ungaro, L. (ed.): Il Museo dei Fori Imperiali nei Mercati di Traiano. Milano: Electa, pp. 118-129.

Ungaro, L. (2011): "Il cantiere del Foro di Augusto, luogo di sperimentazione e modelo formale". En Nogales, T. y RodÀ, I. (eds.): Roma y las provincias: modelo y difusión, vol. 1. Roma: L'Erma di Bretschneider, pp. 43-62.

Ungaro, L.; Milella, M. y Vitti, M. (2004): "Il sistema museale dei Fori Imperiali e i Mercati di Traiano". En Ruiz de Arbulo, J. (ed.): Simulacra Romae. Roma y las capitales provinciales del Occidente Europeo. Tarragona: Edic. El Mèdol, pp. 11-47.

Verzár, M. (1977): Aventicum II. Un temple de culte imperial. Avenches: Association Pro Aventico.

Verzár, M. (1995): "Bemerkungen zum Problem der Kaiserkultstätte in Aventicum". En Arculiana. Ioanni Boegli 65. feliciter peracto. Avenches: LAOTt, pp. 15-31. 
